\title{
Projeto de uma habitação de interesse social com Blocos de terra compactada e ferrocimento
}

\section{Design of a social housing project with Compacted earth blocks and ferro-cement}

DOI: $10.46814 /$ lajdv4n1-016

Recebimento dos originais: 01/01/2021

Aceitação para publicação: 28/02/2022

Márcio Albuquerque Buson

Doutor em Tecnologia da Arquitetura e Urbanismo

Universidade de Brasília

Campus Universitário Darcy Ribeiro ICC Norte Bloco A FAU, Brasília-DF

E-mail: marcio.fau.unb@gmail.com

Aline Curvello da Costa Nemer

Graduação em Arquitetura e Urbanismo

Universidade de Brasília

Campus Universitário Darcy Ribeiro ICC Norte Bloco A FAU, Brasília-DF

E-mail: aline_nemer@hotmail.com

Cícero Portella Castro

Mestrado em Arquitetura e Urbanismo

Universidade de Brasília

Campus Universitário Darcy Ribeiro ICC Norte Bloco A FAU, Brasília-DF

E-mail: ciceroportella@gmail.com

Hana Augusta de Andrade

Graduação em Arquitetura e Urbanismo

Universidade de Brasília

Campus Universitário Darcy Ribeiro ICC Norte Bloco A FAU, Brasília-DF

E-mail: hana.augusta.andrade@gmail.com

Júlio de Paiva Vieira Junior

Graduação em Arquitetura e Urbanismo

Universidade de Brasília

Campus Universitário Darcy Ribeiro ICC Norte Bloco A FAU, Brasília-DF

E-mail: juliodepaivavieira@gmail.com

Lara Agostinho Araújo

Graduação em Arquitetura e Urbanismo

Universidade de Brasília

Campus Universitário Darcy Ribeiro ICC Norte Bloco A FAU, Brasília-DF

E-mail: lara_aa@uol.com.br

\section{Luisa Carvalho Venancio}

Graduação em Arquitetura e Urbanismo

Universidade de Brasília

Campus Universitário Darcy Ribeiro ICC Norte Bloco A FAU, Brasília-DF

E-mail: luvenan@gmail.com 


\section{Maíra Oliveira Guimarães}

Graduada em Arquitetura e Urbanismo pela Universidade de Brasília, com dupla titulação em Architettura per il Restauro e Valorizzazione del Patrimonio pelo Politécnico de Turim

Universidade de Brasília / Politécnico de Turim

Campus Universitário Darcy Ribeiro ICC Norte Bloco A FAU, Brasília-DF

E-mail: maira_og@hotmail.com

\section{Marcelo de Oliveira e Silva}

Graduação em Arquitetura e Urbanismo

Universidade de Brasília

Campus Universitário Darcy Ribeiro ICC Norte Bloco A FAU, Brasília-DF

E-mail: marcelo.o@ outlook.com

\section{Marília Tuler Veloso}

Mestrado em Arquitetura

Universidade Federal de Minas Gerais

Campus Universitário Darcy Ribeiro ICC Norte Bloco A FAU, Brasília-DF

E-mail: mariliatuler@terra.com

\section{Renato Santos Paulinelli Raposo}

Mestrado em Geotecnia

Universidade de Brasília

Campus Universitário Darcy Ribeiro ICC Norte Bloco A FAU, Brasília-DF

E-mail: renatopaulinelli@gmail.com

\section{Rodrigo Resende da Cruz}

Bacharel em Desenho Industrial

Universidade de Brasília

Campus Universitário Darcy Ribeiro ICC Norte Bloco A FAU, Brasília-DF

E-mail: rodrigo.rdacruz@gmail.com

Tamiris Tomimatsu Stevaux

Graduação em Arquitetura e Urbanismo

Universidade de Brasília

Campus Universitário Darcy Ribeiro ICC Norte Bloco A FAU, Brasília-DF

E-mail: tamitomi@uol.com.br

\section{RESUMO}

Este trabalho apresenta a descrição do projeto arquitetônico-construtivo desenvolvido no Escritório Modelo da Faculdade de Arquitetura e Urbanismo da Universidade de Brasília para uma habitação de interesse social em Luanda, Angola. Este projeto foi apresentado no concurso de idéias A HOUSE IN LUANDA: PATIO AND PAVILION, organizado pela Trienal de Arquitectura de Lisboa de 2010. Utilizou-se a arquitetura de terra associada a componentes construtivos pré-fabricados de ferrocimento para produzir mais uma alternativa para habitações de baixo custo, de qualidade e duráveis. Foram exploradas as boas características dos BTCs modulados vazados e com encaixes em associação com componentes de ferrocimento pré-fabricados, como: pré-forma para lajes nervuradas, telhas, reservatórios de água, escadas, bancadas, pias e sanitários compostáveis. São apresentadas as diretrizes de projeto, os sistemas construtivos adotados e o partido arquitetônico do módulo inicial e das possíveis 
expansões, bem como o estudo do tecido urbano resultado da replicação das várias possibilidades de implantação.

Palavras chave: BTC, ferrocimento, habitação popular.

\section{ABSTRACT}

This paper presents the description of the architectural-constructive project developed at the Model Office of the Faculty of Architecture and Urbanism of the University of Brasilia for a social housing project in Luanda, Angola. This project was presented in the competition of ideas A HOUSE IN LUANDA: PATIO AND PAVILION, organized by the Lisbon Architecture Triennale 2010. It used earth architecture associated with prefabricated ferrocement building components to produce another alternative for low cost, quality and durable housing. The good characteristics of the modular hollow and mortise BTCs were explored in association with prefabricated ferrocement components, such as: preform for ribbed slabs, tiles, water tanks, stairs, countertops, sinks and compostable toilets. The design guidelines, the construction systems adopted, and the architectural design of the initial module and of the possible expansions are presented, as well as the study of the urban fabric resulting from the replication of the various implementation possibilities.

Keywords: BTC, ferro-cement, popular housing.

\section{INTRODUÇÃO}

A compreensão de uma obra de arquitetura exige conhecer o objeto social que a mesma reflete, bem como aquilo que caracteriza o sujeito da obra em questão (Svensson, 1992).

Entretanto a arquitetura influencia os sujeitos ao ponto de mudá-los, vezes para melhor vezes para pior, e estes, por sua vez, também têm o poder de ajustar, aperfeiçoar e personalizar a arquitetura.

Cada país, povo, família e indivíduo têm expressões típicas que refletem circunstâncias e características tanto locais quanto pessoais. Surge a questão, como satisfazer a criatividade ao projetar para Luanda uma espécie de habitat simbólico no qual se encontram respostas às necessidades e urgências humanas básicas sem conhecer intimamente os sujeitos das ações, ou melhor, os usuários das futuras habitações?

A solução proposta para a situação imposta pelo concurso de idéias passa pelo que se pode lavrar ou obrar com facilidade, pelo que é maleável e flexível.

Conceber uma habitação unifamiliar de construção radicalmente barata para Luanda resulta, por efeito natural, na utilização do que está disponível localmente de baixo custo; na escolha de técnicas construtivas de fácil execução; no processo de fazer manual do maior número possível de componentes construtivos; e na multifuncionalidade dos elementos que constituem a obra.

Angola é um país com excelentes condições para a utilização da construção em terra, pelo seu clima e pela sua abundante matéria-prima. A introdução de técnicas inovadoras pode desfazer preconceitos em relação a este tipo de construção e promover a sua utilização no mercado da habitação 
(Jalali e Eires, 2008). Atualmente os materiais mais utilizados nas construção são os blocos vazados de concreto e telhas de chapas metálicas.

Para a escolha do material de construção predominante numa obra de interesse social devemse pensar, prioritariamente, nos aspectos de produtividade; na diminuição de custos com outros materiais; na redução de desperdício; na resistência e durabilidade; e na facilidade de manutenção. Portanto, deve-se pensar não só no material, mas no processo e sistema construtivo (Buson, 2007).

Optou-se pelo uso do Bloco de Terra Compactado - BTC. Uma evolução do bloco de adobe que consiste na compactação da terra através de uma prensa, a qual pode ser manual e acionada pela força humana ou hidráulica/elétrica. Os moldes da prensa podem ser variados, o que permite a produção de diferentes tipos de blocos: maciços; vazados; tipo canaleta; meio bloco; com e sem encaixes. Para esse projeto foram utilizados BTCs vazados e com encaixes, como pode ser visto na Figura 1.

Fig.1 - Detalhes construtivos para paredes de BTCs vazados e com encaixes: a) Meio bloco, canaleta e faces do BTC; b) rasgos nos BTCs com serra circular e formão; c) grampos em encontros de paredes; d) abertura para passagem de tubulações; e) concretagem de colunas; f) Assentamento com cola branca; g) corte com arame de tungstênio e colocação de caixa 5x7; h) corte em BTCs para embutir Quadro de Luz (créditos: Buson, 2007).
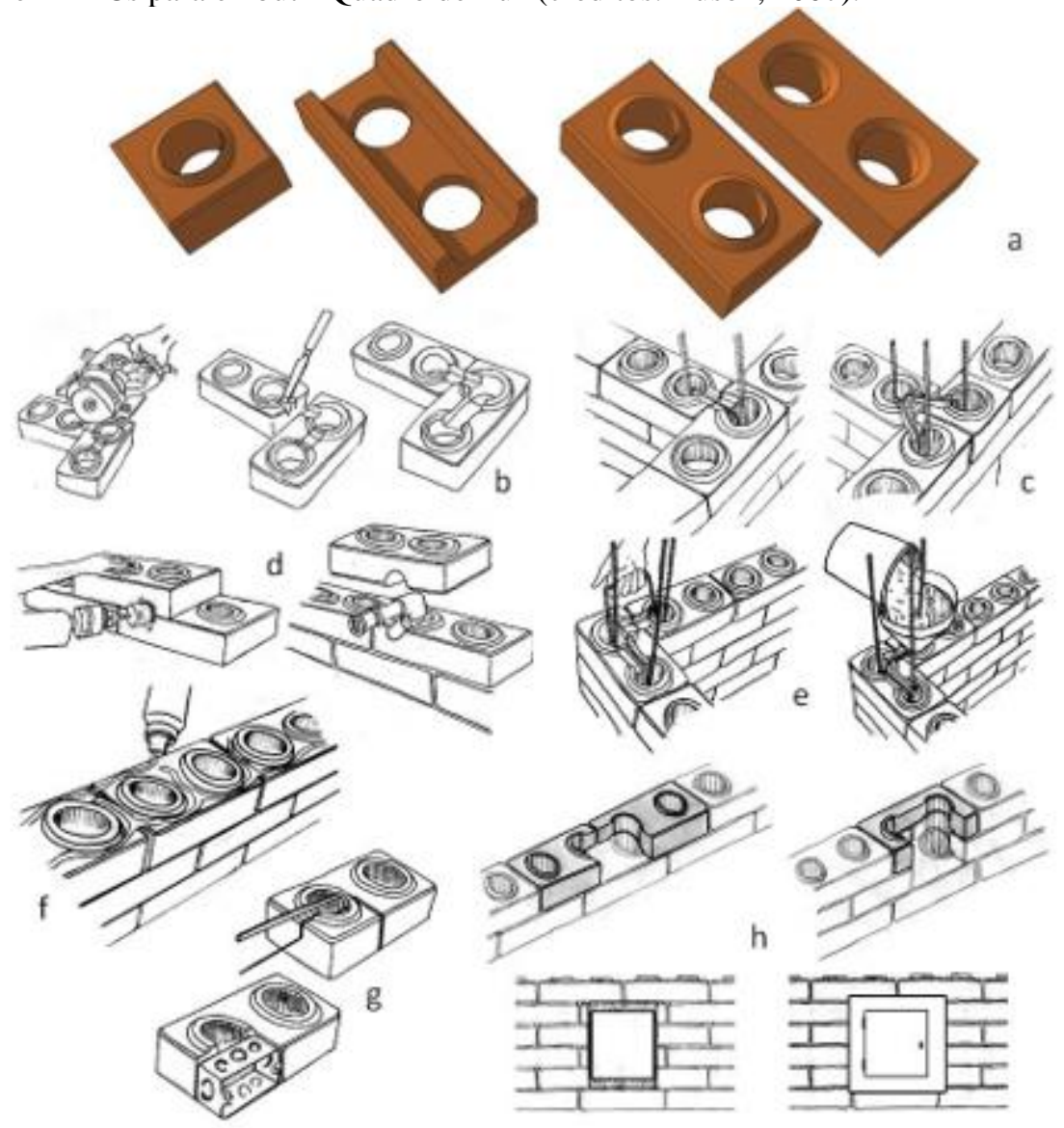

O BTC vazado e com encaixes é um componente construtivo extremamente versátil por desempenhar várias funções. Além de propiciar a vedação e divisão dos ambientes, proporciona 
reduções de custos ao dispensar e/ou minimizar o uso de outros materiais e de algumas etapas de construção. Os BTCs podem ficar aparentes, o que dispensa materiais de revestimento e acabamento; servem de forma para os elementos estruturais; possibilitam a passagem de tubulações e instalações prediais; e dispensam o uso de argamassa de assentamento, pois podem ser assentados com cola branca.

Escolheu-se o ferrocimento - cimento e areia (traço 1:2) e telas metálicas - como material e sistema construtivo para produção dos pisos estruturais; coberturas; vigas calhas; escada; bancadas; lavatórios; pias; tanques; vasos sanitários; e reservatórios de água. Técnica simples e de fácil transmissão e execução.

Tanto o BTC quanto o ferrocimento são recursos à manufatura e à autoconstrução por parte dos futuros moradores.

O componente feito de ferrocimento mais explorado nessa proposta construtiva é a cascaje tetos e pisos feitos de painéis abobadados pré-fabricados, os quais têm a vantagem de economizar material, pois são muito finos, de 1 a $3 \mathrm{~cm}$ de espessura (Lengen, 1997).

Como o próprio nome diz meio casca (telha e/ou forma) meio laje. Proporcionam tetos abobadados e também servem de pré-laje para pisos estruturais nervurados, dispensando escoramentos. Executadas em formas de chapas zincadas e tarugos de madeira, resultam em peças leves que dispensam o uso de equipamentos para sua instalação. Por se tratar de um elemento cuja transmissão térmica é elevada, recomenda-se o uso de camada isolante acima das telhas de cascaje. Essa camada pode ser feita de várias maneiras, Lengen (1997) sugere uma camada de serragem e cimento. Também foram incorporadas às telhas de cascaje aberturas para ventilação e/ou iluminação. Com um custo mínimo agregaram-se novas funções ao componente construtivo.

Outro uso para a cascaje foi para estruturar a escada. Com a utilização de formas laterais simples de madeira, dispostas de cada lado da cascaje, os degraus pré-fabricados de ferrocimento são apoiados para posterior concretagem e fixação.

Estes componentes de ferrocimento são pré-fabricados e este processo pode acontecer individualmente no local de cada obra ou numa central de produção, o que poderia reduzir ainda mais os custos. A exemplo do que foi feito no projeto "Modelo Comunitário para Saneamento Familiar: Boas práticas nos musseques de Luanda”, desenvolvido pela ONG Luta Contra Pobreza Urbana LUPP.

Um sistema de coleta de águas pluviais e outro para tratar as águas servidas foram propostos como alternativas à infra-estrutura urbana, para melhorar a qualidade de vida da comunidade.

Para apoio e suporte das cascajes foram propostas estruturas pré-fabricadas do tipo viga calha de ferrocimento, as quais também terão a função de coleta das águas pluviais. 
A armazenagem das águas das chuvas coletadas ocorrerá em duas caixas d'água de 500 litros localizadas no pavimento superior e em uma cisterna com capacidade para 12.500 litros construída abaixo do pátio central, ambos elementos de ferrocimento.

Um tanque ou canteiro bio-séptico é usado para tratar as águas servidas. Localizado no pátio de trás, ele elimina qualquer resíduo, gerando biomassa, como frutas comestíveis (Soares e Legan, 2009).

Outro sistema proposto como alternativa ecológica é o vaso sanitário seco, do qual se pode extrair adubo. O layout dos sanitários permite aos futuros moradores a opção tanto do vaso seco quanto do vaso com caixa acoplada. O canteiro bio-séptico proposto tem capacidade para absorver qualquer das alternativas.

Fig.2 - Elementos pré-fabricados de ferrocimento e alguns detalhes construtivos (créditos, Buson, 2010).

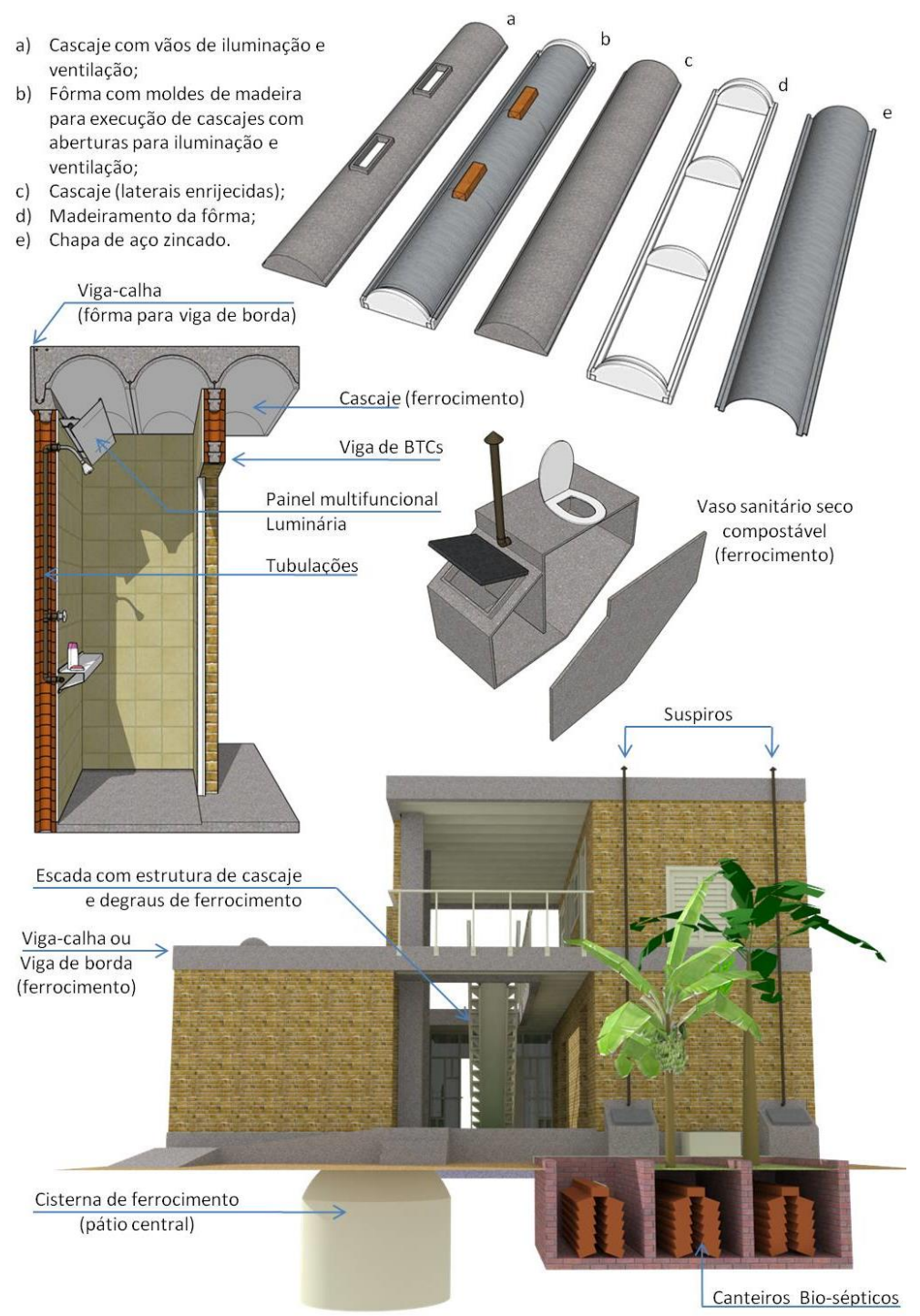




\section{A CASA}

O Edital do concurso define que o projeto deverá contar com a possibilidade das habitações comportarem soluções evolutivas, eventualmente em auto-construção, adaptando-se, assim, à velocidade de transformação do tecido social angolano e de

Luanda como grande metrópole africana que, tendencialmente, será. Também informa que o projeto é para uma "unidade familiar que origine um pátio, com um baixo custo de construção, destinada a famílias em situação de grande carência, comumente constituídas por 7-9 pessoas (Pais, 3 filhos e 2 avós ou Pais, 5 filhos, 2 avós), num terreno de topografia plana, situado no perímetro de Luanda, com dimensões de $10 \mathrm{~m}$ de frente por $25 \mathrm{~m}$ de profundidade. A área de construção até $100 \mathrm{~m}^{2}$.

O desenho surgiu com a tentativa de criar relações estreitas entre interior e exterior, entre coberto e descoberto, entre aberto e fechado e do entendimento de "pátio" como recinto murado e descoberto que vai desde a entrada externa até a construção principal e de "pavilhão" como uma pequena construção por vezes isolada, outras vezes ao meio ou aos lados do corpo principal do edifício.

O desenho proposto delega aos futuros moradores a incumbência de definição de qual será a parte principal de suas casas, os pátios ou os pavilhões.

Os ambientes cobertos ladeiam e dobram suas funções ao também serem usados como muros. O espaço é bem definido, mas não rígido, podendo ser modificado sem perder seu caráter.

A casa é desenhada ao longo de um eixo forte, desobstruído no centro, definindo um espaço de convívio. Este eixo principal conduz à escada, o eixo vertical, ao redor do qual a casa continua a se desdobrar. Um largo e longo ambiente sem obstruções no centro da edificação, onde todos podem se encontrar, com vista do céu, um pedaço de terra, intimidade, a presença da natureza.

A casa se volta para o seu interior ao mesmo tempo em que a ampla entrada se apresenta para a rua e convida o visitante a entrar exatamente pelo núcleo da morada. As relações fundamentais da socialização começam e terminam à escolha dos usuários.

A casa voltada para o seu interior facilita a construção por fases ao diminuir ou eliminar a necessidade de ajustes e reformas no já construído. Os novos pavilhões ou futuras ampliações podem ocorrer de forma flexível e com custos reduzidos. No pavimento superior, por exemplo, a área construída pode ser dobrada e outros quatro cômodos podem surgir bastando apenas transformar as coberturas de cascaje em lajes de piso.

O layout dos ambientes favorece a redução dos custos de construção, como: prateleiras e guarda-roupas de embutir em nichos de paredes de BTCs, todos modulados e com a mesmas dimensões; e os ambientes com aberturas amplas sem portas ou esquadrias. $\mathrm{O}$ fechamento destes ambientes ocorrerá com painéis, feitos de esteiras, fixados em trilhos por detrás de painéis multifuncionais, os quais também possibilitam a redução de custos e facilitam a manutenção das 
instalações elétricas, são fixados nas paredes e servem ao mesmo tempo de luminárias para teto e para parede, além de condutores de fiação e suporte dos trilhos dos painéis esteiras.

Para atender ao programa de necessidades e propiciar que um dos quartos seja utilizado confortavelmente por até cinco crianças uma quinta cama foi adicionada acima do espaço das caixas d'água, o que também propiciou mais espaço para os armários desse quarto. Chega-se a esta cama por uma escada fixada na parede, como num beliche. $\mathrm{O}$ desenho oferece dessa maneira intimidade e conforto aos casais (pais e avós) sem ultrapassar a área máxima de construção.

Fig.3 - Plantas baixas, cortes e fachada. Térreo: hall de entrada; sala de estar; copa/cozinha; banheiro; área de serviço; quarto; escada; pátio com cisterna; e canteiro bio-céptico (fundos). Pavimento superior: quarto casal; quarto triplo (beliche acima dos reservatórios para captação das águas das chuvas). Nas coberturas é possível ver os vãos de iluminação (vidros coloridos) e algumas cascajes cobrindo os vãos de ventilação (créditos, Buson, 2010).
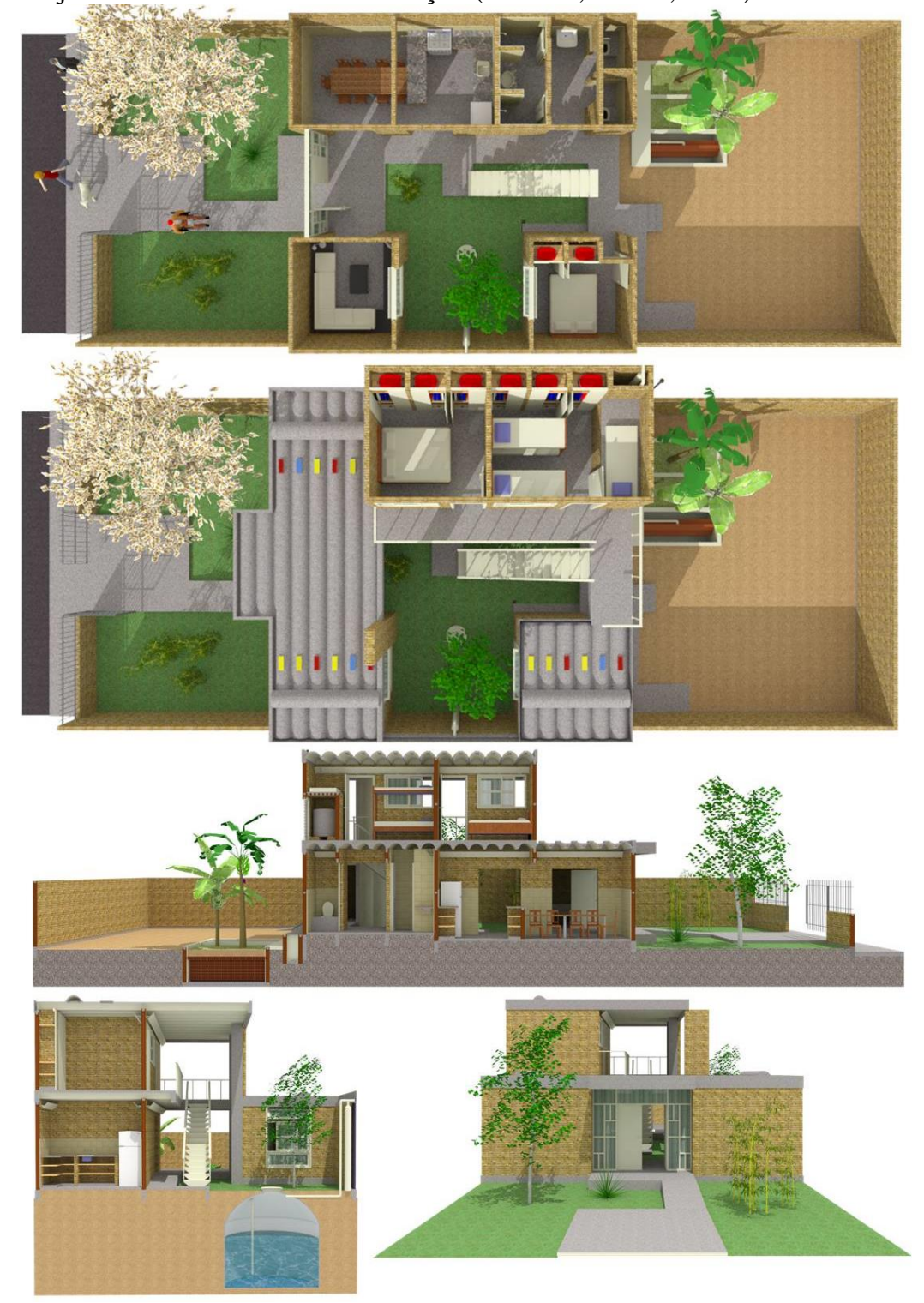


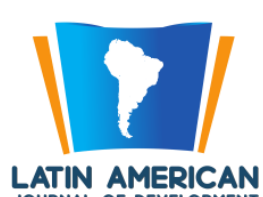

LATIN AMERICAN

Fig.4 - Vistas externas da casa e de uma conformação de tecido urbano; algumas das expansões e ampliações possíveis para os dois pavimentos (créditos, Buson, 2010).

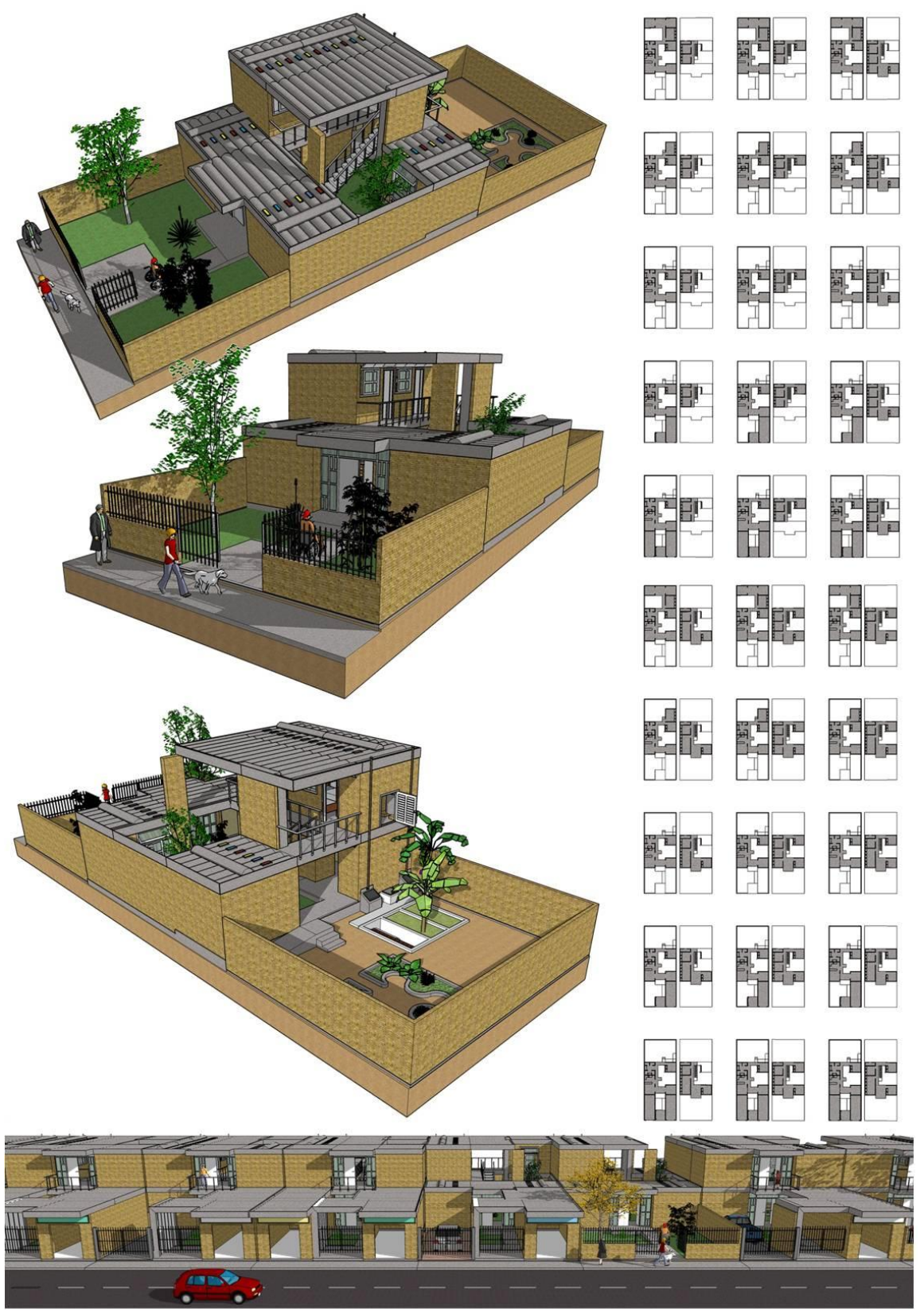

\section{EXPANSÕES}

O desenho simplifica o processo de construção em fases, exigência do concurso de idéias, ao eliminar as necessidades de ajustes e reformas. Novos cômodos ou futuras expansões podem ser construídos de maneira flexível e barata. No segundo piso, por exemplo, a área construída pode dobrar e quatro novos quartos podem ser criados simplesmente ao transformar as cascajes de cobertura em lajes nervuradas de piso. 


\section{TECIDO URBANO}

A lógica de racionalização e sustentabilidade da proposta também está nas possibilidades de agregar valor ao imóvel e gerar renda. $\mathrm{O}$ afastamento proposto entre o módulo inicial da casa e a divisa da rua proporciona a execução futura de módulos que podem servir, por exemplo, para atividades de comércio ou serviço.

A proposta resulta num modelo replicável que pode crescer e ser alterado de acordo com o morador. A capacidade da construção de acomodar diferentes moradores sem perder seu caráter permite um tecido urbano atraente que é diversificado, mas coeso. São muitas as composições e possibilidades espaciais.

\section{AGRADECIMENTOS}

Este trabalho recebeu o apoio do Decanato de Pesquisa e Pós-Graduação da Universidade de Brasília - DPP/UnB, através do Edital 04/2010, para a participação do autor no SIACOT. 


\section{BIBLIOGRAFIA}

Buson, M. (2007). Autoconstrução com tijolos prensados de solo estabilizado. Brasília. Faculdade de Arquitetura e Urbanismo da Universidade de Brasília.

Conselho de Ministros da República de Angola (2009). Decreto promoção e acesso a habitação social (versão preliminar). Angola.

Jalali, S.; e Eires, R. (2008). Inovações científicas de construção em terra crua. Azurém. Universidade do Minho, Departamento de Engenharia Civil.

Lengen, J. v. (1997). Manual do arquiteto descalço. Rio de Janeiro. Fundação TIBÁ.

Soares, A.; Legan, L. (2009). De olho na água: construindo o canteiro bio-séptico e captando água da chuva. Pirenópolis. Ed. Mais Calango.

Svensson, F. (1992). Arquitetura, criação e necessidade: algumas indicações para a formação de arquitetos na República Popular de Angola. Brasília. Universidade de Brasília. 